\title{
Management of Complications of Wrist Arthroplasty and Wrist Fusion.
}

\author{
Michael P. Gaspar \\ The Philadelphia Hand Center, P.C. \\ Patrick M Kane \\ The Philadelphia Hand Center, P.C. \\ Eon K. Shin \\ The Philadelphia Hand Center, P.C.; Thomas Jefferson University
}

Follow this and additional works at: https://jdc.jefferson.edu/orthofp

Part of the Orthopedics Commons

Let us know how access to this document benefits you

\section{Recommended Citation}

Gaspar, Michael P.; Kane, Patrick M; and Shin, Eon K., "Management of Complications of Wrist Arthroplasty and Wrist Fusion." (2015). Department of Orthopaedic Surgery Faculty Papers.

\section{Paper 76.}

https://jdc.jefferson.edu/orthofp/76

This Article is brought to you for free and open access by the Jefferson Digital Commons. The Jefferson Digital Commons is a service of Thomas Jefferson University's Center for Teaching and Learning (CTL). The Commons is a showcase for Jefferson books and journals, peer-reviewed scholarly publications, unique historical collections from the University archives, and teaching tools. The Jefferson Digital Commons allows researchers and interested readers anywhere in the world to learn about and keep up to date with Jefferson scholarship. This article has been accepted for inclusion in Department of Orthopaedic Surgery Faculty Papers by an authorized administrator of the Jefferson Digital Commons. For more information, please contact: JeffersonDigitalCommons@jefferson.edu. 


\section{Management of Complications of Wrist Arthroplasty and Wrist Fusion}

Michael P. Gaspar, M.D.

Clinical Research Fellow in Hand and Upper Extremity Surgery

The Philadelphia Hand Center, P.C.

834 Chestnut Street, Suite G114

Philadelphia, PA 19107

Phone: (804) 3639157

Email: michaelpgaspar@gmail.com

Patrick M. Kane, M.D.

Fellow in Hand and Upper Extremity Surgery

The Philadelphia Hand Center, P.C.

834 Chestnut Street, Suite G114

Philadelphia, PA 19107

Phone: (856) 4651717

Email:pmkkane@gmail.com

Eon K. Shin, M.D.

Assistant Professor of Orthopaedic Surgery

Thomas Jefferson University Hospital

The Philadelphia Hand Center, P.C.

834 Chestnut Street, Suite G114

Philadelphia, PA 19107

Phone: (215) 5213011

Fax: (215) 6292945

Email: ekshin@handcenters.com 


\section{SYNOPSIS}

The human wrist joint is very unique from both a functional and anatomical standpoint. Numerous articulations exist within the wrist that allow for a significant number options for partial wrist fusion and arthroplasty, especially in the case of focal degenerative or posttraumatic arthritis. In cases of pancarpal disease, such as that which is often found in inflammatory conditions, fusion or arthroplasty of the entire wrist joint can also be performed. However, because of the high functional demand of the wrist, many of these surgical options can eventually fail, often leading to devastating complications. This chapter will address the different types of fusions and arthroplasties available for the wrist and discuss the potential complications associated with each. Methods to prevent these complications are presented, and finally those to treat them once they have occurred will also be discussed.

\section{KEY WORDS}

Wrist Complications Arthroplasty Arthrodesis Fusion Total Partial Revision

\section{KEY POINTS}

-The wrist joint is contains many bony articulations, allowing for many different options of partial (or total) fusion or arthroplasty to treat painful arthritis.

-The high functional demands of the wrist make many of these procedures susceptible to complications and failure.

-Preventative measures and careful patient selection are of utmost importance in avoiding complications.

-Despite vigilant pre-operative measures, complications often still do occur.

-Though complications can sometimes be managed conservatively, they often require surgical management which can be quite extensive in many cases. 


\section{INTRODUCTION}

Arthrodesis has long been a solution for painful end-stage arthritis, not just of the wrist, but for a number of joints in the body $(1,2)$. Successful arthrodesis of any joint can offer a stable and pain-free construct, though typically at the expense of mobility and some degree of functionality. This is of special concern with the wrist, where motion and functionality are more important than the ability to bear weight when compared to joints of the lower extremity.

Wrist arthroplasty in its various forms is a newer alternative for treatment of painful arthritis, approximating the motion of a healthy wrist (3). As implant design and surgical techniques have improved, the indications for wrist arthroplasty have concomitantly expanded. However, even with the latest implants and techniques, the durability of wrist arthroplasty components is limited. Thus, arthroplasty is typically reserved for older patients or those with fewer physical demands (4).

Together, wrist arthrodesis and arthroplasty form a spectrum of available treatments for endstage arthritis about the wrist. Because of the numerous articulations about the wrist, both arthroplasty and arthrodesis each have their own specific indications, corresponding to the location of disease.

This chapter will first review the different types of fusions and arthroplasties available for the wrist. This will include a discussion regarding the indications and contraindications for performing each surgery. The chapter will conclude by presenting complications associated with each procedure type, detailing the current methods to address these complications, including 
preventative measures to avoid such complications, and tactics to treat them once they have occurred.

\section{INDICATIONS}

Prior to the advent of wrist arthroplasty for treatment of end stage arthritis, arthrodesis was considered the standard treatment (5). It is widely considered that the development of wrist arthroplasty techniques have lagged behind other large joint reconstructive procedures, such as the hip, knee, and shoulder, because overall outcomes following wrist arthrodesis with respect to symptom palliation were acceptable (5-8). Eventually, as interest grew in finding a solution for painful end stage wrist arthritis that relieved pain and maintained motion, wrist arthroplasty techniques developed and are now mostly considered an alternative to fusion. Since there is significant overlap in the indications for performing either of these two procedures, it is often just as judicious to consider the contraindications.

The wrist joint is unique when compared to other major joints of the body in that numerous bones and articulations comprise the totality of the joint. When compared to other major joints that may present as candidates for arthroplasty, it is not surprising that there are a number of partial or limited options to consider before performing a total fusion or arthroplasty. Thus,

during the initial workup and planning, it is important to correlate patient complaints with physical examination findings and radiographs to target the areas that need to be addressed.

For patients with post-traumatic arthritis, imaging the contralateral side for comparison and preoperative planning can be helpful (9). When assessing the patient and evaluating radiographs, 
particular attention should be paid to areas with higher known incidence of pathology such as the distal radioulnar joint (DRUJ), the scapholunate (SL) interval, the scaphotrapeziotrapezoid (STT) joint, and the triangular fibrocartilage complex (TFCC) $(3,9,10)$.

Although standard wrist radiographs are generally sufficient for evaluation and surgical planning, advanced imaging is often necessary to assess details of specific disease processes. Magnetic resonance imaging (MRI) can help to distinguish Kienbock disease from ulnar impaction syndrome (11). Computed tomography (CT) can also be useful in further delineating degenerative processes when standard radiographs are difficult to interpret. Most degenerative arthritis seen in the wrist is localized about the scaphoid, so a detailed history and physical examination can help to elucidate such information.

Once the extent of the disease is revealed and surgical intervention is deemed appropriate, the surgeon must take into consideration the medical, demographic, and even socioeconomic factors that may affect the outcome of surgery, particularly, with respect to contraindications.

\section{SURGICAL OPTIONS: ARTHRODESIS}

Arthrodesis procedures about the wrist can range from single joint fusion to total wrist fusion, depending on the extent of the disease at the time of surgery and any predicted progression of disease. As a significant proportion of degenerative disease about the wrist involves the scaphoid or one of its articulations, a majority of these limited wrist fusion options involve the scaphoid. 


\section{RADIOCARPAL ARTHRODESIS}

Both radioscapholunate (RSL) and radiolunate (RL) arthrodesis are typically performed as a treatment of progression of post-traumatic conditions (12). RSL arthrodesis is often the initial treatment of choice for patients with a history of intraarticular distal radius fractures who progress to significantly painful post-traumatic arthrosis (13). It can also be a treatment of choice for stabilization of carpal collapse deformities in those with a stable midcarpal joint. Similarly, RL arthrodesis in most commonly used to treat post-traumatic arthrosis at the radiolunate joint, particularly in patients with deformity in the lunate fossa of the radius (14) and in rheumatoid patients to reseat the lunate into the fossa in the radius to correct ulnar subluxation of the wrist. Both RSL and RL arthrodesis can also be used to treat ulnar translocation of the carpus following significant ligamentous disruption. As both types of limited arthrodesis rely on a stable midcarpal joint for optimal post-operative function, the presence of midcarpal disease or instability is an absolute contraindication for either procedure (12).

(insert Figures 1-3)

\section{MIDCARPAL ARTHRODESIS}

STT arthrodesis is a mainstay treatment for STT arthritis $(12,15)$ as well as early stage Kienbock disease prior to the onset of carpal collapse (15-17). It has also been used for treatment of chronic SL dissociation but with mixed results (18). Conversely, scaphocapitate arthrodesis is rarely used to treat arthritis, but rather to provide a functional result similar to treatment options for STT arthritis, allowing for its use in the reduction of the SL interval and for offloading the lunate in the treatment of Kienbock disease $(19,20)$. Scaphoid excision with four-corner fusion 
can be used in treating scapholunate advanced collapse (SLAC) or scaphoid nonunion advanced collapse (SNAC) $(21,22)$.

(insert Figures 4 and 5)

TOTAL WRIST ARTHRODESIS

Finally, total wrist arthrodesis is indicated for primary treatment of pancarpal arthritis, particularly in those patients who are high demand. It can also be used as a salvage procedure for failed limited wrist fusions as well as partial or total wrist arthroplasties. Studies have generally shown excellent results with long-term outcomes following wrist arthrodesis $(23,24)$. (insert Figure 6)

\section{SURGICAL OPTIONS: ARTHROPLASTY}

Just as with arthrodesis, there are a range of options with arthroplasty from partial to complete. Again, the partial arthroplasty options provide a more targeted approach depending on the location and extent of the disease, whereas total wrist arthroplasty is typically performed to address pancarpal arthritis at the wrist.

\section{RESECTION ARTHROPLASTY}

For disease located at the DRUJ, there are a number of arthroplasty options, including the Darrach procedure, hemiresection interpostion arthroplasty (HIT), the Sauvé-Kapandji procedure, and distal ulna arthroplasty (25-30). Note that DRUJ pathology can result from a number of etiologies, including degenerative, post-traumatic, inflammatory, and congenital (29). It is also important to keep in mind that DRUJ dysfunction, forearm instability, and ulnar impaction syndrome often all coexist, (31) so surgical treatment should be selected accordingly. 
The Darrach procedure, the oldest form of resection arthroplasty in the wrist, describes the resection of the distal ulna just proximal to the sigmoid notch with preservation of surrounding soft-tissue structures $(25,32)$. The goal is to provide pain relief while maintaining post-operative stability (25). The hemiresection interposition technique involves removal of just the radial aspect of the ulna and insertion of soft tissue in the resultant void (28). HIT depends on the integrity of the soft tissue stabilizers, particularly the TFCC, and thus should only be performed with an intact TFCC $(28,33)$. The Sauvé-Kapandji technique involves fusion of the distal radioulnar joint and resection of a portion of the ulna just proximal to the sigmoid notch $(26,27)$. This creates a proximal ulnar pseudoarthrosis allowing forearm rotation, eliminates DRUJ pain and instability, and prevents ulnar translation of the carpus $(26,27)$.

\section{(insert Figure 7)}

Proximal row carpectomy (PRC) is a resection arthroplasty technique for treatment of radiocarpal disease secondary to SNAC, SLAC, and Kienbock disease $(34,35)$. Because PRC is essentially used to address the same issues as four corner fusion, there have been a number of studies comparing outcomes of the two procedures with variable results $(22,36,37)$. (insert Figures 8 and 9)

\section{IMPLANT ARTHROPLASTY}

Options for implant arthroplasties of the wrist continue to expand as technology improves and as longer-term outcomes are made available from older prostheses. For DRUJ pathology, there are again multiple implant options. Partial ulnar head arthoplasty involves resection of focal areas of 
diseased ulna and placement of the prosthesis with minimal soft-tissue disruption (38). It is contraindicated following Darrach resection because the entire distal ulna would have already been excised.

Total ulnar head arthroplasty involves a complete resection of the ulnar head with the insertion of a stemmed implant and is intended to treat instability in addition to pain $(39,40)$. In cases of complete DRUJ disruption, there are total DRUJ arthroplasty implants available. This procedure completely replaces the DRUJ with an implant that is affixed to both the ulna and the radius with a mobile bearing between the two (30). Both the ulnar head implant and the DRUJ replacement are typically performed for failed resection arthroplasty and represent salvage procedures. (insert Figure 10)

Total wrist arthroplasty, like arthrodesis, addresses pancarpal arthritis rather than focal areas of disease. The materials used for implants, as well as modes of fixation, have evolved over the years. As a result, the survivorship of these implants has improved. However, it is important to emphasize that survivorship of even the latest models of implants is highly dependent on patient selection, and their use in patients who exceed their designed capabilities can lead to implant failure, which is often catastrophic.

Decades of "trial-and-error" with total wrist arthroplasty technology has led to the current total wrist replacement devices that include a proximal component affixed to the distal end of the radius with a stemmed component and a distal component fixed to the distal carpus and metacarpals (41-43). Just as in total joint replacements in other large joints, patient selection is of 
paramount importance. Ideal surgical candidates are those with low-demand lifestyles seeking pain-relief without completely giving up motion at the wrist. There are also hemiarthroplasty options in which only a proximal component—inserted into the distal radius—is used, typically performed in conjunction with PRC (44-45).

Though osteoarthritis (OA) and rheumatoid arthritis (RA) patients compose the majority of total wrist replacement candidates, there are some even within those groups for which this surgery is contraindicated. Some patients with OA continue to be physically active and may not be willing to limit their activities to accommodate their new prosthesis. Patients with highly reactive RA and concomitantly poor bone quality may represent poor candidates owing to their high likelihood of failure. Other contraindications include those unable to adhere to post-operative restrictions (such as those with dementia or other mental illness) or those who depend on their upper extremities for ambulation either chronically or acutely.

(insert Figure 11)

\section{COMPLICATIONS AND MANAGEMENT: ARTHRODESIS}

As with fusion at other joints of the body, complications from wrist arthrodesis are thought to be largely preventable and highly dependant on patient selection. Nonunion is the most likely complication after wrist fusion, and its occurrence is multi-factorial $(46,47)$. The larger surface area of the wrist articulations relative to other joints in the body is one factor that must be considered for successful fusion. This is usually addressed by meticulous removal of all articular cartilage and direct apposition of the surfaces. A second key factor in the development of union is the stability of the fixation. 
For total wrist fusion that addresses degenerative and post-traumatic conditions, dorsal compression plating has provided the most promising results with regards to high union rates and is therefore considered the standard (24,48-52). However, in cases of inflammatory arthritis, there is increased concern for implant failure with plating due to poor bone quality, in addition to concerns with wound healing. Many of these patients can have particularly thin skin on the dorsum of the hand. Thus, the use of Steinmann pins, Kirschner wires, screws and/or intramedullary rods have been advocated in these patients along with extensive synovectomy and ulnar head excision (53-56). Similarly, the optimal construct for intercarpal fusions are less definitive, with variable results noted between pin and screw fixation versus circular compression plating (57-59).

With regards to patient selection, factors that affect bone quality should be evaluated. Patients with severely osteopenic bone and those with a history of smoking have much higher reported rates of nonunion (47). Similarly, the type and quality of the bone graft that is used should be considered. Though there is no good comparative literature evaluating the different bone graft substrates, anecdotally many surgeons find that the excised carpal bones are too sclerotic for optimal use as autograft and advocate the use of cancellous autograft from iliac crest or distal radius $(60,61)$. If nonunion still occurs, the mainstay treatment is revision fixation with bone graft (47).

(insert Figure 12) 
An alternative or adjunct to revision surgery may be the use of an implantable bone stimulator, which shows promise in animal models (62-64) and variable success in treatment of non-unions at other sites $(65,66)$. Though data regarding their successful use in treating nonunion specifically for wrist fusion are limited, it has been reported (67).

Another concerning complication following wrist arthrodesis is infection. Superficial infections occur far more frequently, with a rate of approximately 3\%, versus deep infections at roughly $0.5 \%(46,48,57)$. Superficial infections often stem from wound issues, particularly caused by the thin skin that is present on the dorsum of the wrist in many patients (68). Higher-risk patients include those with pre-existing diabetes and those with compromised immune function, either acquired through disease or iatrogenic such as RA patients who take steroids and/or other immune modulators (69-71).

Deep infections, though far less likely, can often lead to more devastating problems. Significant hematoma formation as a result of the extensive bony preparation required for fusion can serve as a nidus for deep infection (47). Thus, careful hemostasis performed intraoperatively can have profound effects for prevention of deep infection. Additionally, a well made post-operative splint and compression dressing can help to minimize hematoma formation. Literature on infections in the wrist arthrodesis is somewhat limited, but the most common organisms involved are skin pathogens Staphylococcus aureus and Streptococcus epidermis (68). Thus, universally standard precautions such as aseptic technique and prophylactic antibiotics are also critical. 
When deep infections occur, operative irrigation and debridement with removal of hardware is the treatment of choice, followed by a course of antibiotics tailored to cultures obtained from the site of infection (68). Typically, an antibiotic regimen of at least 4 weeks in duration is necessary to eradicate the bony infection (68). Consultation with an infectious disease specialist is always warranted, especially if the patient is immunocompromised or suffers from other medical comorbidities that preclude optimal treatment options (72). When infection occurs before bony union is present, there is the additional challenge of keeping the wrist stabilized while the infection clears prior to re-implantation of any hardware. Literature is limited regarding this situation, but the best treatment in this case would be placement of a temporary external fixator while the patient undergoes appropriate antibiotic therapy to treat the infection $(68,72)$.

Hardware complications, though not as devastating as nonunion and infection, may still pose a significant challenge. Some studies using dorsal compression plating report symptomatic hardware with either painful prominence or bursitis as high as one-third to two-thirds of patients and frequently require hardware removal $(24,49,51)$. It is recommended that the dorsal plate not be removed prior to clear evidence of bony union, with some guidelines recommending that the plate be maintained at least six months and even up to 12 months post-operatively (47).

Injuries to neurovascular structures may occur, with dorsal sensory branches of the ulnar and radial nerves at highest risk $(46,48,58)$. Both plating and pin fixation place these structures at risk, and to date there is no study that demonstrates that one method has a lower sensory nerve injury rate than the other. To prevent such injuries from occurring during an open dorsal approach, it is recommended that the sensory branches are kept within the flaps and that 
excessive retraction is avoided (47). If pins are placed outside of the dorsal surgical incision, a separate small open incision should be used particularly on the radial side, where the dorsal sensory radial nerve branches are found.

Additionally, carpal tunnel syndrome is a well-known complication following wrist fusion with some studies presenting rates as high as $10 \%$, half of which eventually require a carpal tunnel release (48). As a result, some surgeons advocate a carpal tunnel release at the time of the wrist fusion surgery.

Arthritis in adjacent joints is a complication that is of particular concern in limited fusions. Following STT fusions, adjacent trapeziometacarpal and radiocarpal arthritis has been reported (17,73-75). Careful screening of potential limited fusion patients for pre-existing adjacent arthrosis is an important preventative measure. Additionally, it is critical that the scaphoid remain anatomically reduced relative to the radius to prevent development of adjacent joint disease. STT fusion also has a relatively high rate of resultant radial styloid impingement, noted by some to be as high as one-third of patients (76). The treatment of choice is radial styloidectomy, with some advocating routine styloidectomy at the time of the STT fusion $(74,75)$.

Ulnocarpal impaction may also occur and is typically more prevalent when fusion is performed in excessive ulnar deviation (46). When this complication is recognized in ulnar positive patients, it is ideally treated with a joint-leveling procedure such as an ulnar shortening osteotomy (77). In those patients with inadequate DRUJ function, ulnar neutral/negative 
variance, and lower demand requirements, simple excision of the distal ulna is often adequate (77).

\section{COMPLICATIONS AND MANAGEMENT: ARTHROPLASTY}

Potential complications following arthroplasty of the wrist are also numerous and can be devastating. The complications that arise in the setting of resection arthroplasty are discussed separately from those that involve implant placement.

The evolution of different resection arthroplasties addressing pathology at the DRUJ can essentially be traced back to the original Darrach procedure $(25,32)$. Though outcomes following distal ulna resection are acceptable with regards to pain, motion, and grip strength (25), they can be associated with a number of complications. Most notably, instability of the ulnar remnant is observed which leads to radioulnar impingement. Additionally, loss of the ulnar support of the carpus can lead to carpal collapse or even ulnar translocation of the carpus.

A number of techniques have been described to remedy ulnar instability following excessive distal ulna resection. Tenodesis using weaves of a proximally-based strip of extensor carpi ulnaris (ECU) and a distally-based strip of flexor carpi ulnaris (FCU) tendon can successfully stabilize a symptomatically unstable ulna (78) and is thought to be superior than using either ECU or FCU alone $(79,80)$. The use of Achilles tendon allograft as an interposition graft has also shown success in a small series (81-84). Additionally, transfer of the pronator quadratus to the dorsum of the ulna for use as an interposition graft has also been described with good outcomes $(85,86)$. 
In addition to the soft-tissue stabilization procedures just mentioned, both ulnar head and DRUJ replacement implants can be used as salvage for failed resection arthroplasty of the distal ulna (40,87-89). Long-term outcomes following ulnar head replacement for treatment of failed distal ulnar resection have shown promise even greater than ten years after the initial surgery (88). Biomechanical studies have also shown ulnar head replacement to be superior to soft-tissue stabilization after failed Darrach (90).

Similarly, five-year follow up after DRUJ prosthesis placement showed sustained improvement in patients' reported pain and functionality (89). It is worth noting, however, that this particular study included patients with other causes of DRUJ dysfunction in addition to those who had failed previous resection arthroplasty. It should also be noted that DRUJ replacement is a more extensive and technically challenging procedure than the previously mention salvage procedures for failed Darrach (91).

Resection arthroplasty techniques such as the Sauvé Kapandji technique and HIT were initially developed as an alternative to the Darrach procedure (26-28,33). It is important to realize that these are alternative procedures to the Darrach distal ulna resection and not salvage procedures after failed Darrach procedure. As the results of the distal ulna resection as described by Darrach will preclude either the Sauvé-Kapandji or HIT from being performed. Both of these procedures have their own potential complications. 
Nonunion or fixation failure at the attempted DRUJ fusion site can occur in the Sauvé-Kapandji technique with increased likelihood in patients with poor bone stock or quality, as is often seen in patients with RA (27). A modified version of this technique is termed shelf arthroplasty by Masada. This procedure removes a portion of the distal ulna, rotates it perpendicular to the long axis of the radius, and fixes it into the sigmoid notch via compression screw. It has been reported with good outcomes after minimum five-year follow-up (92).

Both the original and modified Sauvé-Kapandji techniques have the potential complications of radioulnar convergence at the remaining ulnar stump and of reossification at the pseudoarthrosis site. As a preemptive measure to prevent ulnar impingement, it is strongly recommended that the ulna is resected as distally as possible, as the ulnar side of the radius becomes more ridge-like to accommodate the interosseous membrane as one moves proximally (93). This morphology is thought to contribute to the painful symptoms of impingement. A salvage technique, in which the pseudoarthrosis is taken down, uses an intercalary graft is to restore ulnar length, and HIT is performed to provide rotation, has been described with successful outcomes in a small set of patients (94).

Though there is no established regimen for treatment of reossification at the site of the original psuedoarthrosis. One study reported acceptable outcomes with medical management using antiinflammatory steroids in a small number of patients. Simple excision of the reossification site can also be performed (93). 
Implant arthroplasties of the wrist share many of the same complications seen in other joints of the body and can prove quite challenging to treat. The majority of partial implant arthroplasties of the wrist (partial or total ulnar head replacement, DRUJ total arthroplasty) are still performed as a salvage procedure as described above, but there is an increase of their use as primary treatment of DRUJ pathologies or congenital disorders such as Madelung deformity and EhlersDanlos syndrome (91). Regardless of their indication for use, the complications that arise are typically the same.

For ulnar head prostheses, the most common reported complication is recurrent instability $(87,88)$. This is often the result of inadequate soft-tissue coverage and can be treated with reinforcement of the soft-tissue repair, such as with a retinacular flap (88). If that is not possible to perform, such as in a multiply operated wrist lacking adequate soft tissue, conversion to a total DRUJ arthroplasty can be considered. One study reports a single case of stem loosening, which was subsequently corrected with revision to a larger diameter stem (88). This same study reported another case of heterotopic ossification first noted radiographically nearly four years post-operatively that was treated conservatively.

Similar results were found in a study looking at DRUJ arthroplasty with a single patient experiencing heterotopic ossification at the distal ulna, also treated non-operatively (91). Implant loosening has not been consistently noted with newer DRUJ implant technologies. There have not been any reports of significant deep infection with DRUJ arthroplasty requiring implant removal, but that may be secondary to the relatively small number of surgeries that are performed. 
(insert Figure 13)

The ultimate choice for salvage of the unstable forearm that has failed the aforementioned methods would be creation of a radioulnar synostosis and a one-bone forearm $(95,96)$. In addition to eliminating forearm rotation, the poor overall outcomes of this procedure cause many to consider it a last resort for treatment of painful forearm instability (95-97).

Despite continuous advances in implant technology and surgical techniques for total wrist arthroplasty, complications may still occur. Instability and implant loosening are the most common TWA complications but are often preventable. Newer technologies that rely on the distal component fixed to the carpus with concomitant intercarpal fusion have significantly reduced the incidence of loosening compared to older models fixed into the metacarpal shafts $(98,99)$.

When loosening does occur, it is possible that revision arthroplasty can correct the problem if the patient's bone stock is reasonable. However, the safest and most generally accepted solution is conversion to a wrist fusion. Positive outcomes have been reported using both iliac crest autograft and femoral head allograft to address bone voids when converting to a fusion. The use of femoral head allograft avoids the morbidity associated with harvesting iliac crest $(100,101)$. A wrist arthrodesis plate as well as a post-operative splint should be used to ensure bony union prior to activity $(102,103)$.

Instability can also be predicted by patient selection, as post-operative dislocation is most often a result of excessive joint laxity and/or soft-tissue imbalance. RA patients are especially 
susceptible, as the combination of poor bone stock and attenuated wrist capsule due to synovitis is likely to contribute to a very lax wrist joint.

If instability occurs, the surgeon must evaluate technique and component selection. As with loosening, it is possible that revision of one or all of the components may provide the solution, again if there is adequate remaining bone stock. When instability is thought to be the result of an attenuated wrist capsule, there have been positive outcomes reported with the use of soft-tissue allograft to augment the capsule (4). If an acute trauma has caused instability or dislocation, a trial of immobilization with either casting or a spanning external fixator may be successful (98). When the aforementioned techniques do not correct the instability, or if revision is not feasible, conversion to arthrodesis is the most ideal treatment (103-105).

(insert Figure 14)

Intraoperative complications during TWA include fracture and tendon laceration. Proper preparation of the radius prior to implantation of the radial component is vital to avoid fracture. If the intramedullary canal is inadequately prepared or the cortical bone is weakened, then placement of the press-fit radial component may cause fracture $(3,6)$. Thus it is recommended to use fluoroscopy judiciously to ensure proper alignment of broaches to the medullary canal $(3,4,106)$. In addition, it is recommended to prepare the canal so that the trial component can be fully seated with minimal force. If fracture does occur, circumferential cerclage wires should be used to stabilize the fracture, and post-operative rehabilitation should be adjusted accordingly by delaying motion until the fracture heals. Unfortunately, these precautions can eventually lead to loss of motion due to capsular stiffness. 
Unlike the radial component, the distal carpal component usually has a stem in addition to screws. If fracture does occur distally, bone grafting and longer screws that span the fracture should be placed (4). If there is inadequate or poor quality bone at the stem, then use of cement should be considered.

Intraoperative extensor tendon lacerations usually occur while raising the extensor retinaculum, especially in a previously operated wrist where scarring to the overlying skin is common (3). Raising the skin and retinaculum together in a single flap can prevent this from occurring $(3,4,6)$. If tendon laceration does occur, repair should be performed intraoperatively, and again the rehabilitation protocol should be adjusted accordingly $(4,6)$.

Infection is a rare complication in TWA, and like fusions, often coincides with wound complications. Preemptive measures to guard against hematoma formation are similar, including adequate hemostasis with the tourniquet deflated and post-operative compression dressing. It is also recommended that a closed-suction drain is placed for removal one to two days postoperatively $(101,102,105)$. When deep infection does occur, the treatment is analogous to arthroplasty of other large joints. If cultures and sensitivities of the offending organism reveal an infection that can be effectively treated with antibiotics, then a trial of surgical debridement and appropriate antibiotic therapy may be warranted in an early post-operative infection $(105,107)$. Late infection should be treated with resection arthroplasty followed by total wrist fusion once the infection has been deemed cleared $(101,102)$. Antibiotic cement may be used to maintain wrist height until definitive fusion is performed $(101,102)$. Though there has been some literature 
of comparable efficacy of serial aspirations of the septic wrist versus open irrigation and debridement, this is not likely to be effective in this scenario due to seeding of the prosthesis $(107,108)$.

The final potential complication of TWA discussed here is pathology of the DRUJ. In the setting of a painful wrist with pancarpal arthritis, it can be difficult to elucidate any symptomatic DRUJ pathology from other causes of pain due to arthritis. In such cases, it may be most judicious to leave the DRUJ intact at the time of arthroplasty, while informing the patient that additional surgery may be indicated in the future to address the DRUJ (99). This can be particularly wise in those patients with OA with ulnar neutral/negative variance, so as not to further exacerbate the variance with removal of a portion of distal ulna $(3,4)$.

When DRUJ pathology does develop after TWA, the most straightforward is simple ulnar head excision. This is especially the case in patients with RA who have a high incidence of progressing to DRUJ arthritis following TWA, and those with significant radiocarpal disease that has resulted in positive ulnar variance, as preparation of the distal radius for TWA will only worsen the variance $(3,4,106)$. The incidence of symptomatic ulnar stump instability is much lower in patients with TWA than those with isolated resection arthroplasties, but if needed soft tissue interposition and ECU/FCU tenodesis can be performed (78-80). Finally, the simultaneous use of DRUJ and total wrist implants have been performed sparingly with little data at this time, but there is concern for metal on metal wear that may develop between the two implants. 
Despite the extensive list of complications that can arise from performing wrist arthroplasty, it is still accepted as a worthwhile procedure by surgeons and patients alike. Perhaps the most telling sign is that patients who have had one of each procedure typically show preference to the side with the arthroplasty (42). Many of the complications that can arise either from arthroplasty or fusion of the wrist are in fact preventable, and prophylactic measures combined with stringent patient selection and surgical planning can go a long way in minimizing the risks of this constantly evolving field. 


\section{REFERENCES}

1. Carroll RE, Dick HM. Arthrodesis of the wrist for rheumatoid arthritis. J Bone Joint Surg 1971;53A: 1365-9.

2. Haddad RJ, Riordan DC. Arthrodesis of the wrist: a surgical technique. J Bone Joint Surg 1967;49A: 950-4.

3. Adams BD. Total wrist arthroplasty. J Am Soc Surg Hand. 2001;1:236-248.

4. Anderson MC, Adams BD. Total wrist arthroplasty. Hand Clin 2005;21:621- 630.

5. Ritt MJ, Stuart PR, Naggar L, et al. The early history of arthroplasty of the wrist: from amputation to total wrist implant. J Hand Surg Br 1994;19(6):778-82.

6. Rosenfeld JF, Nicholson JJ. History and design considerations for arthroplasty around the wrist. Hand Clin. 2013 Feb;29(1):1-13.

7. Volz RG. The development of a total wrist arthroplasty. Clin Orthop Rel Res 1976;116:209-14.

8. McElfresh E. History of arthroplasty. In: Petty W, editor. Total joint replacement. Philadelphia: WB Saunders; 1991. p. 3- 18.

9. Jebson PJL, Adams BD. Wrist arthrodesis: review of current techniques. J Am Acad Orthop Surg 2001; 9(1):53-60.

10. Murphy DM, Khoury JG, Imbriglia JE et al. Comparison of arthroplasty and arthrodesis for the rheumatoid wrist. J Hand Surg Am Jul 2003;28:570-6.

11. Hayter CL, Gold SL, Potter HG. Magnetic resonance imaging of the wrist: bone and cartilage injury. J Magn Reson Imaging. 2013 May;37(5):1005-19

12. Taleisnik J. Subtotal arthrodeses of the wrist joint. Clin Orthop Relat Res. 1984 JulAug;(187):81-8

13. Nagy L, Büchler U. Long-term results of radioscapholunate fusion following fractures of the distal radius. J Hand Surg Br. 1997 Dec;22(6):705-10.

14. Stanley JK, Boot DA. Radio-lunate arthrodesis. J Hand Surg Br. 1989 Aug;14(3):283-7.

15. Ishida O, Tsai TM Complications and results of scapho-trapezio-trapezoid arthrodesis. Clin Orthop Relat Res. 1993 Feb;(287):125-30 
16. Watson HK, Monacelli DM, Milford RS, Ashmead D IV. Treatment of Kienböck's disease with scaphotrapezio-trapezoid arthrodesis. J Hand Surg Am. 1996 Jan;21(1):9-15

17. Meier R, van Griensven M, Krimmer H. Scaphotrapeziotrapezoid (STT)-arthrodesis in Kienbock's disease. J Hand Surg Br 2004;29:580-4.

18. Kleinman WB. Long-term study of chronic scapho-lunate instability treated by scaphotrapezio-trapezoid arthrodesis. J Hand Surg Am. 1989 May;14(3):429-45.

19. Luegmair M, Saffar P. Scaphocapitate arthrodesis for treatment of scapholunate instability in manual workers. J Hand Surg Am. 2013 May;38(5):878-86

20. Luegmair M, Saffar P. Scaphocapitate arthrodesis for treatment of late stage Kienbock disease. J Hand Surg Eur Vol. 2014 May;39(4):416-22

21. Dacho A, Grundel J, Holle G, German G, Saurbier M. Long term results of midcarpal arthrodesis in the treatment of scaphoid nonunion advanced collapse (SNAC-Wrist) and scapholunate advanced collapse (SLAC—Wrist). Ann Plast Surg 2006;56 (2):139-44, Feb.

22. Mulford JS, Ceulemans LJ, NamD, et al. Proximal row carpectomy vs four corner fusion for scapholunate (SLAC) or scaphoid nonunion advanced collapse (SNAC) wrists: a systematic review of outcomes. J Hand Surg Br 2009;34(2):256-63.

23. Solem H, Berg NJ, Finsen V. Long term results of arthrodesis of the wrist: a 6-15 year follow up of 35 patients. Scand J Plast Reconstr Surg Hand Surg. 2006;40(3):175-8.

24. Field J, Herbert TJ, Prosser R. Total wrist fusion. A functional assessment. J Hand Surg Br 1996;21:429-33.

25. Tulipan DJ, Eaton RG, Eberhart RE: The Darrach procedure defended: Technique redefined and long-term follow-up. J Hand Surg Am 1991;16(3):438-444.

26. Taleisnik J. The Sauve'-Kapandji procedure. Clin Orthop Relat Res 1992;275:110-23.

27. Slater RR Jr: The Sauvé-Kapandji procedure. J Hand Surg Am 2008;33(9): 1632-1638.

28. Glowacki KA: Hemiresection arthroplasty of the distal radioulnar joint. Hand Clin 2005;21(4):591-601.

29. Murray PM: Current concepts in the treatment of rheumatoid arthritis of the distal radioulnar joint. Hand Clin 2011; 27(1):49-55.

30. Scheker LR: Implant arthroplasty for the distal radioulnar joint. J Hand Surg Am 2008;33(9):1639-1644. 
31. Szabo RM: Distal radioulnar joint instability. J Bone Joint Surg Am 2006; 88(4):884-894.

32. De Witte PB, Wijffels M, Jupiter JB, Ring D: The Darrach procedure for posttraumatic reconstruction. Acta Orthop Belg 2009;75(3):316-322.

33. Ahmed SK, Cheung JP, Fung BK, Ip WY: Long term results of matched hemiresection interposition arthroplasty for DRUJ arthritis in rheumatoid patients. Hand Surg 2011;16(2):119-125.

34. Richou J, Chuinard C, Moineau G, et al. Proximal row carpectomy: long-term results. Chir Main 2010;29(1):10-5.

35. Elfar JC, Stern PJ. Proximal row carpectomy for scapholunate dissociation. J Hand Surg Br 2011; 36(2):111-5.

36. Cohen MS, Kozin SH. Degenerative arthritis of the wrist: proximal row carpectomy versus scaphoid excision and four-corner arthrodesis. J Hand Surg Am 2001;26:94-104.

37. Wyrick JD, Stern PJ, Kiefhaber TR. Motion-preserving procedures in the treatment of scapholunate advanced collapse wrist: proximal row carpectomy versus four-corner arthrodesis. J Hand Surg Am 1995;20:965-70.

38. Garcia-Elias M: Eclypse: Partial ulnar head replacement for the isolated distal radio-ulnar joint arthrosis. Tech Hand Up Extrem Surg 2007;11(1):121-128.

39. Berger RA: Indications for ulnar head replacement. Am J Orthop (Belle Mead NJ) 2008;37(8 suppl 1):17-20.

40. De Smet L, Peeters T. Salvage of failed Sauvé-Kapandji procedures with an ulnar head prosthesis: report of three cases. J Hand Surg 2003;28B:271-273.

41. Nydick JA, Greenberg SM, Stone JD et al. Clinical outcomes of total wrist arthroplasty. J Hand Surg Am 2012;37:1580-4.

42. Vicar AJ, Burton RI. Surgical management of the rheumatoid wrist-fusion or arthroplasty. J Hand Surg 1986;11A:790-797.

43. Boeckstyns ME, Herzberg G, Merser S. Favorable results after total wrist arthroplasty: 65 wrists in 60 patients followed for 5-9 years. Acta Orthop 2013;84:415-9.

44. Culp RW, Bachoura A, Gelman SE et al. Proximal row carpectomy combined with wrist hemiarthroplasty. JWS 2012;1:39-46.

45. Boyer JS, Adams B. Distal radius hemiarthroplasty combined with proximal row carpectomy: case report. Iowa Orthop J 2010;30:168-73. 
46. Zachary SV, Stern PJ. Complications following AO/ASIF wrist arthrodesis. J Hand Surg [Am] 1995; 20(2):339-44

47. Wysocki RW, Cohen MS. Complications of limited and total wrist arthrodesis. Hand Clin. 2010 May;26(2):221-8

48. Hastings H II, Weiss AP, Quenzer D, et al. Arthrodesis of the wrist for post-traumatic disorders. J Bone Joint Surg Am 1996;78:897-902.

49. O'Bierne J, Boyer MI, Axelrod TS. Wrist arthrodesis using a dynamic compression plate. J Bone Joint Surg Br 1995;77:700-4.

50. Hartigan BJ, Nagle DJ, Foley MJ. Wrist arthrodesis with excision of the proximal carpal bones using the AO/ASIF wrist fusion plate and local bone graft. J Hand Surg [Br] 2001;26(3):247-51.

51. Sagerman SD, Palmer AK. Wrist arthrodesis using a dynamic compression plate. J Hand Surg Br 1996;21:437-41.

52. Meads BM, Scougall PJ, Hargreaves IC. Wrist arthrodesis using a Synthes wrist fusion plate. J Hand Surg [Br] 2003;28(6):571-4.

53. Clayton ML, Ferlic DC. Arthrodesis of the arthritic wrist. Clin Orthop 1984;187:89-93.

54. Mikkelsen OA. Arthrodesis of the wrist joint in rheumatoid arthritis. Hand 1980;12(2):149-53.

55. Papaioannou T, Dickson RA. Arthrodesis of the wrist in rheumatoid disease. Hand 1982;14(1): 12-6.

56. Masada K, Yasuda M, Takeuchi E, et al. Technique of intra-medullary fixation for arthrodesis of the wrist in rheumatoid arthritis. Scand J Plast Reconstr Surg 2003;37(3):155-8.

57. Shin AY. Four-corner arthrodesis. J Am Soc Surg Hand 2001;1:93-111.

58. Vance MC, Hernandez JD, Didonna ML, et al. Complications and outcome of fourcorner arthrodesis: circular plate fixation versus traditional techniques. J Hand Surg Am 2005;30:1122-7.

59. Kendall CB, Brown TR, Millon SJ, et al. Results of four-corner arthrodesis using dorsal circular plate fixation. J Hand Surg Am 2005;30:903-7.

60. Wood MB. Wrist arthrodesis using dorsal radial bone graft. J Hand Surg [Am] $1987 ; 12: 208-12$ 
61. Weiss APC, Wiedeman G, Quenzer D, et al. Upper extremity function after wrist arthrodesis. J Hand Surg [Am] 1995;20A:813-7.

62. Brighton CT, Friedenberg ZB, Mitchell EI, Booth RE. Treatment of Nonunion with Constant Direct Current. Clin Orthop Relat Res. 1977 May;(124):106-23.

63. Dimitriou R, Babis GC. Biomaterial osseointegration enhancement with biophysical stimulation. J Musculoskelet Neuronal Interact 2007;7(3):253-65.

64. Yonemori K, Matsunaga S, Ishidou Y, Maeda S, Yoshida H Early effects of electrical stimulation on osteogenesis. Bone. 1996 Aug;19(2):173-80

65. Mollon B, da Silva V, Busse JW, Einhorn TA, Bhandari M. Electrical stimulation for long-bone fracture-healing: a meta-analysis of randomized controlled trials. J Bone Joint Surg. Am 2008; 90(11): 2322-2330

66. Saxena A, DiDomenico LA, Widtfeldt A, Adams T, Kim W. Implantable electrical bone stimulation for arthrodeses of the foot and ankle in high-risk patients: a multicenter study. J Foot Ankle Surg. 2005 Nov-Dec;44(6):450-4.

67. Nydick JA, Watt JF, Garcia MJ et al. Clinical outcomes of arthrodesis and arthroplasty for the treatment of post-traumatic wrist arthritis. J Hand Surg Am 2013;38:899-903

68. Gaston RG, Kuremsky MA. Postoperative infections: prevention and management. Hand Clin. 2010 May;26(2):265-80

69. Gunther SF, Gunther SB. Diabetic hand infections. Hand Clin 1998;14(4):647-56.

70. Glickel SZ. Hand infections in patients with acquired immunodeficiency syndrome. J Hand Surg 1988;13(5):770.

71. Gonzalez MH, Nikoleit J, Weinzweig N, et al. Upper extremity infections in patients with the human immunodeficiency virus. J Hand Surg Am 1998; 23:348-52.

72. Zalavras CG, Marcus RE, Levin LS, et al. Management of open fractures and subsequent complications. J Bone Joint Surg Am 2007; 89(4):884-95

73. Fortin PT, Louis DS. Long-term follow-up of scaphoid-trapezium-trapezoid arthrodesis. J Hand Surg Am 1993;18:675-81.

74. Wollstein R, Watson HK. Scaphotrapeziotrapezoid arthrodesis for arthritis. Hand Clin 2005;21:539-43, vi.

75. Watson HK, Wollstein R, Joseph E, et al. Scaphotrapeziotrapezoid arthrodesis: a followup study. J Hand Surg Am 2003;28:397-404. 
76. Rogers WD, Watson HK. Radial styloid impingement after triscaphe arthrodesis. J Hand Surg Am 1989; 14:297-301

77. Trumble TE, Easterling KJ, Smith RJ. Ulnocarpal abutment after wrist arthrodesis. J Hand Surg Am 1988;13:11-5.

78. Breen TF, Jupiter JB: Extensor carpi ulnaris and flexor carpi ulnaris tenodesis of the unstable distal ulna. J Hand Surg Am 1989;14(4):612-617.

79. Goldner JL, Hayes MG. Stabilization of the remaining ulna using one-half of the extensor carpi ulnaris tendon after resection of the distal ulna. Orthop Trans 1979;3:330-331

80. Tsai TM, Stilwell JH. Repair of chronic subluxation of the distal radioulnar joint (ulnar dorsal) using flexor carpi ulnaris tendon. J Hand Surg Br. 1984 Oct;9(3):289-94.

81. Sotereanos DG, Gobel F, Vardakas DG, Sarris I. An allograft salvage technique for failure of the Darrach procedure: a report of four cases. J Hand Surg Br. 2002;27(4):317e321.

82. Sotereanos DG, Papatheodorou LK, Williams BG. Tendon allograft interposition for failed distal ulnar resection: 2- to 14-year follow-up. J Hand Surg Am. 2014;39(3):443e448.

83. Greenberg JA, Sotereanos D. Achilles allograft interposition for failed Darrach distal ulna resections. Tech Hand Upper Ext Surg. 2008;12(2):121e125.

84. Papatheodorou LK, Rubright JH, Kokkalis ZT, Sotereanos DG. Resection interposition arthroplasty for failed distal ulna resections. J Wrist Surg. 2013;2(1):13e18.

85. Ruby LK, Ferenz CC, Dell PC. The pronator quadratus interposition transfer: an adjunct to resection arthroplasty of the distal radioulnar joint. J Hand Surg Am. 1996 Jan;21(1):60-5.

86. Bain GI, Heptinstall RJ, Webb JM, Madsen PV. Hemiresection of the distal ulna by means of pronator quadratus interposition and volar stabilization. Tech Hand Up Extrem Surg. 2007 Mar;11(1):83-6.

87. van Schoonhoven J, Fernandez DL, Bowers WH, Herbert TJ. Salvage of failed resection arthroplasties of the distal radioulnar joint using a new ulnar head prosthesis. J Hand Surg 2000;25A:438-446.

88. van Schoonhoven J, Mühldorfer-Fodor M, Fernandez DL, Herbert TJ . Salvage of failed resection arthroplasties of the distal radioulnar joint using an ulnar head prosthesis: longterm results. J Hand Surg Am. 2012 Jul;37(7):1372-80 
89. Scheker LR: Implant arthroplasty for the distal radioulnar joint. J Hand Surg Am 2008;33(9):1639-1644.

90. Sauerbier M, Hahn ME, Berglund LJ, An KN, Berger RA. Biomechanical evaluation of the dynamic radioulnar convergence after ulnar head resection, two soft tissue stabilization methods of the distal ulna and ulnar head prosthesis implantation. Arch Orthop Trauma Surg. 2011 Jan;131(1):15-26

91. Savvidou C, Murphy E, Mailhot E, Jacob S, Scheker LR. Semiconstrained distal radioulnar joint prosthesis. J Wrist Surg. 2013 Feb;2(1):41-8

92. Fujita S, Masada K, Takeuchi E, Yasuda M, Komatsubara Y, Hashimoto H: Modified Sauvé-Kapandji procedure for disorders of the distal radioulnar joint in patients with rheumatoid arthritis. J Bone Joint Surg Am 2005;87(1):134- 139.

93. Lluch A The sauvé-kapandji procedure. J Wrist Surg. 2013 Feb;2(1):33-40

94. Ross M, Thomas J, Couzens G, Coleman S. Salvage of the unstable Sauvé-Kapandji procedure: a new technique. Tech Hand Up Extrem Surg. 2007 Mar;11(1):87-92.

95. Allende C, Allende BT: Posttraumatic one-bone forearm reconstruction: A report of seven cases. J Bone Joint Surg Am 2004;86(2):364-369.

96. Peterson CA II, Maki S, Wood MB: Clinical results of the one-bone forearm. J Hand Surg Am 1995;20(4):609-618.

97. Jacoby SM, Bachoura A, Diprinzio EV, Culp RW, Osterman AL. Complications following one-bone forearm surgery for posttraumatic forearm and distal radioulnar joint instability. J Hand Surg Am. 2013;38(5):976-982.

98. Lorei MP, Figgie MP, Ranawat CS, et al. Failed total wrist arthroplasty. Analysis of failures and results of operative management. Clin Orthop Rel Res 1997;34(2):84-93.

99. Divelbiss BJ, Sollerman C, Adams BD. Early results of the Universal total wrist arthroplasty in rheumatoid arthritis. J Hand Surg Am 2002;27(2):195-204.

100. Younger EM, Chapman MW. Morbidity at bone graft donor sites. J Orthop Trauma 1989;3(3):192-5.

101. Laurie SW, Kaban LB, Mulliken JB, Murray JE. Donorsite morbidity after harvesting rib and iliac bone. Plast Reconstr Surg 1984;73(6):933-8.

102. Ferlic DC, Jolly SN, Clayton ML. Salvage for failed implant arthroplasty of the wrist. J Hand Surg [Am] 1992;17(5):917-23. 
103. Rizzo M, Ackerman DB, Rodrigues RL, Beckenbaugh RD. Wrist arthrodesis as a salvage procedure for failed implant arthroplasty. J Hand Surg 2011;36E:29 -33.

104. Beer TA, Turner RH. Wrist arthrodesis for failed implant arthroplasty. J Hand Surg 1997;22(4): 685-93.

105. Mater WY, Jafari SM, Restrepo C, et al. Preventing infection in total joint arthroplasty. J Bone Joint Surg Am 2010;92(Suppl 2):36-46.

106. Adams BD. Complications of wrist arthroplasty. Hand Clin. 2010 May;26(2):213-20

107. Murray PM. Septic arthritis of the hand and wrist. Hand Clin 1998;14:579 -587, viii.

108. Sammer DM, Shin AY. Comparison of arthroscopic and open treatment of septic arthritis of the wrist. J Bone Joint Surg 2009;91A: 1387-1393. 


\section{FIGURE LEGEND}

Figure 1. (A) AP, (B) oblique, and (C) lateral views of the right wrist in a patient with significant arthrosis at the radiocarpal joint following a distal radius fracture sustained remotely.

Figure 2. Intraoperative images of the same patient. (A) Decorticated surfaces of the radius (R), scaphoid (S), and lunate (L) in preparation for fusion. (B) Radioscapholunate arthrodesis using two angled $2.4 \mathrm{~mm}$ distal radius plates (Synthes Ltd., Paoli, PA) and cancellous iliac crest autograft.

Figure 3. Post-operative flouroscopic images of the same patient.

Figure 4. (A) Pre- and (B) post-operative images of a patient with scaphotrapeziotrapezoid arthritis treated with arthrodesis.

Figure 5. (A) Pre- and (B) post-operative radiographs of a patient with scapholunate advanced collapse treated with scaphoid excision and four-corner intercarpal arthrodesis.

Figure 6. (A) Pre- and (B) post-operative radiographs demonstrating significant pancarpal and distal radioulnar joint arthritis treated with total wrist arthrodesis and distal ulna resection.

Figure 7. Hemiresection interpostion arthroplasty for distal radioulnar joint arthritis.

Figure 8. Advanced Kienbock's disease. Note the significant collapse and sclerosis of the lunate seen on the AP view.

Figure 9. Post-operative radiographs of the same patient following proximal row carpectomy.

Figure 10. Ulnar implant arthroplasty.

Figure 11. (A) Pre- and (B) post-operative radiographs demonstrating significant pan-carpal and distal radioulnar joint arthritis treated with total wrist arthroplasty and distal ulna resection.

Figure 12. (A) Initial post-operative images for treatment of a trans-styloid trans-scaphoid perilunate fracture-dislocation. (B) Following scaphoid excision with four-corner arthrodesis, the patient demonstrated continued pain and limited mobility. (C) A total wrist arthrodesis as a salvage procedure allowed the patient to return back to work with good bony union and satisfactory hardware alignment.

Figure 13. Total wrist arthrodesis and distal ulna arthroplasty using a Scheker implant (Aptis Medical, Glenview KY).

Figure 14. (A) Total wrist arthroplasty with distal ulna resection. The patient did well and was lost to follow-up until more than six years later, when he presented with gradually increasing wrist pain. (B) Radiographs demonstrated catastrophic failure at the distal component. The patient is scheduled for a revision wrist arthrodesis with femoral head allograft. It is suspected 
that gradual polyethylene wear and subsequent osteolysis led to the failure of fixation of the distal component. 